\title{
Age-adjusted Charlson comorbidity index in recurrent glioblastoma: a new prognostic factor?
}

\author{
Melanie Barz ${ }^{1 *}\left(\mathbb{0}\right.$, Stefanie Bette ${ }^{2,3}$, Insa Janssen ${ }^{1,4}$, A. Kaywan Aftahy ${ }^{1}$, Thomas Huber ${ }^{5}$, \\ Friederike Liesche-Starnecker ${ }^{6}$, Yu-Mi Ryang ${ }^{1,7}$, Benedikt Wiestler ${ }^{2}$, Stephanie E. Combs , $^{8,9,10}$, \\ Bernhard Meyer ${ }^{1}$ and Jens Gempt ${ }^{1}$
}

\begin{abstract}
Background: For recurrent glioblastoma (GB) patients, several therapy options have been established over the last years such as more aggressive surgery, re-irradiation or chemotherapy. Age and the Karnofsky Performance Status Scale (KPSS) are used to make decisions for these patients as these are established as prognostic factors in the initial diagnosis of GB. This study's aim was to evaluate preoperative patient comorbidities by using the age-adjusted Charlson Comorbidity Index (ACCl) as a prognostic factor for recurrent GB patients.

Methods: In this retrospective analysis we could include 123 patients with surgery for primary recurrence of GB from January 2007 until December 2016 (43 females, 80 males, mean age 57 years (range 21-80years)). Preoperative age, sex, ACCl, KPSS and adjuvant treatment regimes were recorded for each patient. Extent of resection (EOR) was recorded as a complete/incomplete resection of the contrast-enhancing tumor part.

Results: Median overall survival (OS) was 9.0 months ( $95 \% \mathrm{Cl} 7.1-10.9$ months) after first re-resection. Preoperative KPSS $>80 \%(P<0.001)$ and EOR $(P=0.013)$ were associated with significantly improved survival in univariate analysis. Including these factors in multivariate analysis, preoperative KPSS $<80$ (HR 2.002 [95\% Cl: 1.246-3.216], $P=0.004$ ) and EOR are the only significant prognostic factor (HR 1.611 [95\% Cl: 1.036-2.505], $P=0.034$ ). ACCI was not shown as a prognostic factor in univariate and multivariate analyses.
\end{abstract}

Conclusion: For patients with surgery for recurrent glioblastoma, the ACCl does not add further information about patient's prognosis besides the well-established KPSS and extent of resection.

Keywords: Age-adjusted Charlson comorbidity index, Recurrent glioblastoma, Surgery, Prognostic factor

\section{Background}

Glioblastoma (GB) multiforme is the most aggressive primary brain tumor in adults with a median age of 64 years at the time of diagnosis $[1,2]$. Although there have been therapeutic advances over the last decades, the local

\footnotetext{
*Correspondence: melanie.barz@tum.de

${ }^{1}$ Department of Neurosurgery, Technical University Munich, School

of Medicine, Klinikum rechts der Isar, Munich, Germany

Full list of author information is available at the end of the article
}

progression within weeks to months is the main reason for treatment failure [3-5]. In the last years, more therapy options have been developed for recurrent disease, such as more aggressive surgery, re-irradiation, or chemotherapy [6-8]. The Karnofsky Performance Status Scale (KPSS) is one of the most important prognostic factors regarding the overall survival (OS) of newly diagnosed GB patients. In addition to the patients' age $[9,10]$, it is used for decision-making in recurrent GB as well. Younger patients who have obtained functional 
independence benefit more from recurrent surgery than older patients with a reduced KPSS. Besides age and KPSS, complete resection stands out as the most important prognostic factor [11, 12]. Due to demographic changes within the expanding elderly population, an increasing incidence rate of GB and recurrent GB among elderly people has been observed [1]. The patients' increasing age is usually associated with a higher rate of comorbidities and this burden can be assessed by the Charlson comorbidity index (CCI), a validated score to estimate mortality in patients with multiple comorbidities [13-15]. In 1994, this could be extended by adding the age, so that the age-adjusted CCI was created [16]. Although the (age-adjusted) CCI initially proved its worth in internal diseases, in recent studies it has also proved to be a useful tool for tumour diseases in addition to the well-known and established KPSS. Initial steps in this direction have been taken by various workgroups in the case of relapsing tumors of different entities. So, the group of Martinez could show that in the case of relapsed Hodgkin's lymphoma in patients older than 50 years, a $\mathrm{CCI}>1$ is associated with poor OS and progression-free survival, independently of age [17]. Other publications that cover relapsing neck cancer have produced similar results: If the frequency or severity of comorbidity increases, survival progressively decreases $[18,19]$. The aim of this study was to evaluate patient comorbidities by using the age-adjusted Charlson Comorbidity Index (ACCI) as a prognostic factor in recurrent GB.

\section{Methods}

This retrospective, non-interventional bicentric study was approved by the medical ethics committee of the Technical University Munich (5625-12) and is in accordance with the ethical standards of the 1964 Declaration of Helsinki and its later amendments [20].

\section{Patient population}

From 189 possible eligible patients, 33 were excluded due to progression from a lower grade of glioma and another 23 patients were excluded because of second or third recurrence, 10 were excluded due to biopsy. 123 consecutive patients with recurrent GB (WHO IV) between January 2007 and December 2016 met our inclusion criteria: surgery for primary recurrence of $\mathrm{GB}$ with available ACCI, preoperative age, sex, KPSS, and pre-/postoperative MRI. We retrospectively reviewed all the clinical data of these 123 patients and analyzed the comorbidities by using the age-adjusted ACCI (Fig. 1). In detail, the CCI takes into account 19 conditions with a score for each comorbidity from 1 to 6 , depending on the risk of death. By using the age-adjusted form of the CCI, the score additionally receives the specific weighting of age. This means that a 50-year-old patient receives one additional point for every decade (e.g., in 50-59years, 1 point; 60-69 years, 2 points; $70-79$ years, 3 points), and these age points are added to the CCI score (e.g., 0, 1, 2, 3, etc.) $[14,16]$. Using a Roc curve analysis and the Youden index, we were able to detect a cut-off for the ACCI at 6.5 (Figure). Additionally, we analyzed preoperative sex and functional status quantified by the KPSS. Recurrence and progression were evaluated by MRI using the RANO criteria [21]. Recurrent neurosurgical resection was performed using intraoperative neuromonitoring, neuronavigation, and 5-aminolevulinic acid (ALA) with the aim of maximum resection of the contrast-enhancing tumor part. In patients with inoperable tumor recurrence, a biopsy was performed for histopathological diagnosis. Patients with biopsy were not included in this study. Within the first surgery, molecular pathological findings were analyzed according to the WHO criteria of 2016 [22] (i.e., O-6-methylguanine-DNA-methyltransferase [MGMT] promotor methylation (35/123; of which MGMT methylation could be detected in 15 patients

189 patients
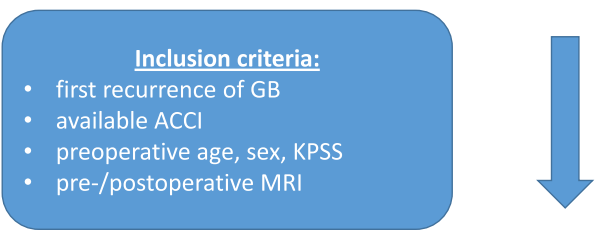

Exclusion:

Fig. 1 Flowchart of patient-selection process 
[23], mutation status of isocitrate dehydrogenase [IDH] (26/123; no patient showed an IDH mutation) [22]). In the case of recurrence, no further investigations were made. Due to oncological aftercare, adjuvant treatment regimes were recorded in 120 patients. 27 of these 120 patients had combined radiochemotherapy according to the STUPP regime (Fig. 2). EOR was recorded for all patients (complete/incomplete resection of the contrastenhancing tumor part).

\section{Statistical analysis}

Statistical analysis was performed using IBM SPSS Statistics, Version 24.0 and 26.0 (SPSS Inc., IBM Corp., Armonk, NY, USA). Non-normally distributed data are shown as median and interquartile range (IR), and normally distributed variables are shown as mean and standard deviation. OS was assessed with the Kaplan Meier method in univariate analysis (log-rank). Multivariate survival analysis was performed using a cox proportional hazard regression model. A $p$-value of $<.05$ was assumed to be statistically significant.

\section{Results}

\section{Patients and clinical data}

The patient population comprises 123 patients (mean age at surgery 57 years, range $21-80$ years, 80 male/ 43 female) with surgery for recurrent GB (Table 1). The median
Table 1 Baseline patient and tumor characteristics

\begin{tabular}{ll}
\hline Age & $\mathbf{5 7}$ years $\mathbf{( \pm \mathbf { 1 0 . 6 } )}$ \\
\hline Sex, female & $43 / 123$ \\
KPSS preoperative & $80.0(\mathrm{IR} 70.0-90.0)$ \\
KPSS postoperative & $70.0(\mathrm{IR} 60.0-90.0)$ \\
$\begin{array}{l}\text { Tumor hemisphere } \\
\quad \text { right }\end{array}$ & \\
$\quad$ left & $58 / 123$ \\
ACCl & $55 / 123$ \\
$\quad$ avialable & \\
$\quad$ median & 123,123 \\
Surgery & $4.0(\mathrm{Cl} 3-6)$ \\
$\quad$ intraoperative neuromonitoring & \\
5-ALA & $87 / 123$ \\
$\quad$ neuronavigation & $44 / 123$ \\
Extent of resection & $109 / 123$ \\
$\quad$ complete resection & \\
incomplete resection & \\
Adjuvant treatment & $45 / 123$ \\
Stupp scheme & $78 / 123$ \\
radiotherapy only & \\
chemotherapy only & $25 / 123$ \\
\hline
\end{tabular}

normally distributed variables shown as mean +/- standard deviation, nonnormally distributed as median (interquartile range)

KPSS Karnofsky Performance Status Scale

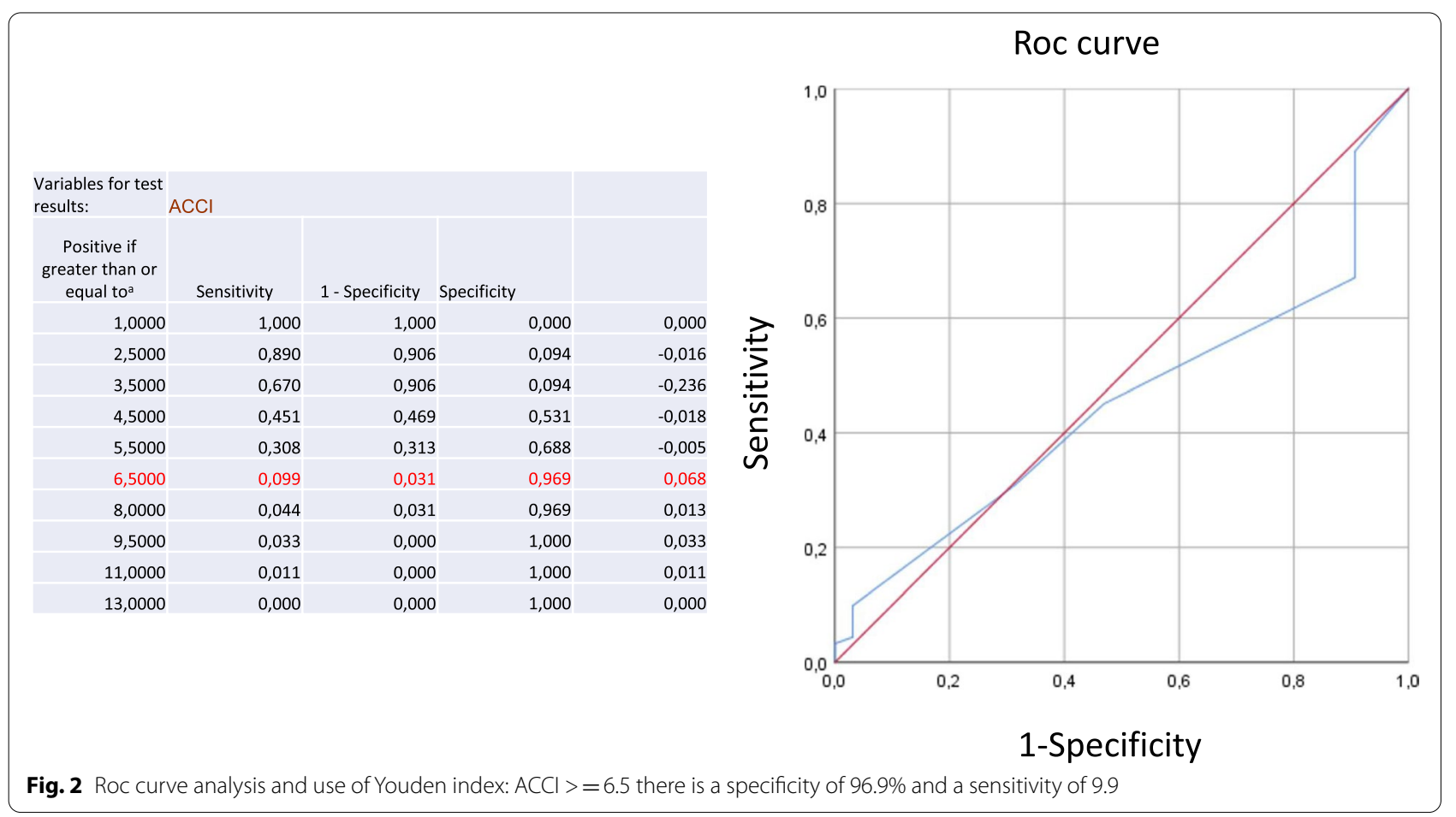


preoperative KPSS was $80 \%$ (range $50-100 \%$ ), and the median postoperative KPSS was 70\% (range 0-100\%).

\section{$\mathrm{ACCl}$ and outcome}

Median OS was 9.0 months (95\% CI 7.1-10.9) after surgery for first recurrence of GB. Median preoperative ACCI was 4.0 (95\% CI 3-6).

\section{Univariate survival analyses}

Preoperative KPSS $\geq 80 \%$ was associated with significantly improved survival after operation for first recurrence of GB $(P=0.002)$. Preoperative ACCI was included in the further analysis as a continuous variable and could not reach statistical significance for survival analysis after the operation for first recurrence of GB. Patients with complete re-resection showed significantly improved survival after surgery $(P=0.013)$. Age, with a cutoff at 65 years, was not significant in relation to OS from operation for first recurrence of GB until death $(P=0.445)$ (Figs. 3 and 4$)$.
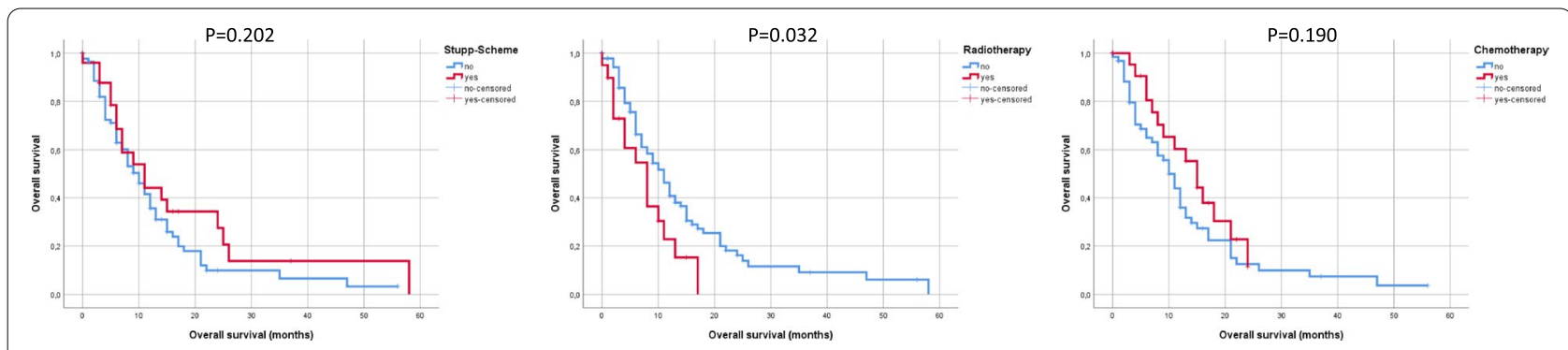

Fig. 3 OS according to adjuvant therapy
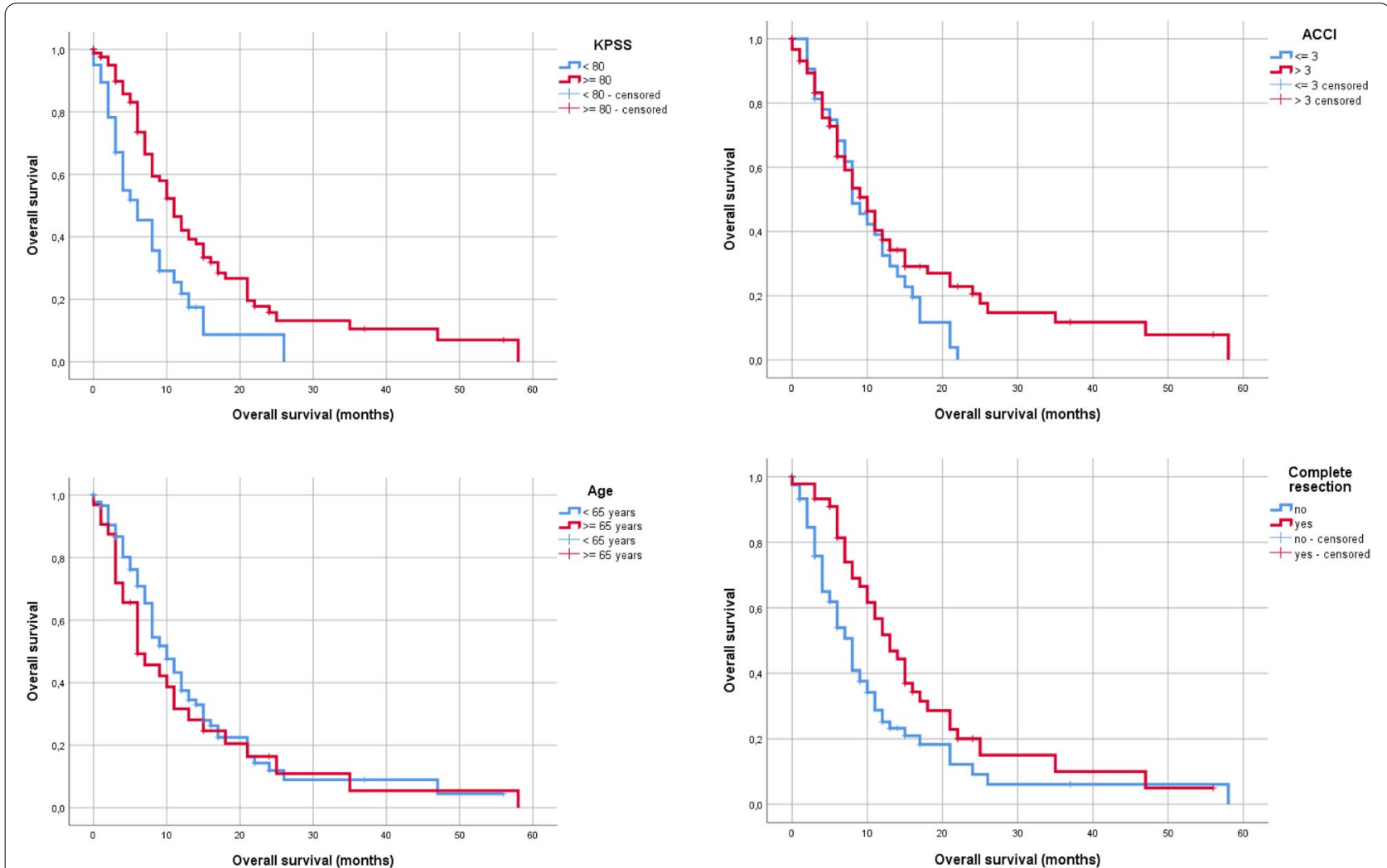

Fig. 4 OS according to the age-adjusted Charlson Comorbidity Index (here as an example with cut-off of 3) as well as in relation to the KPSS in GB patients 


\section{Multivariate survival analyses}

Multivariate survival analysis included the following parameters: age $(</ \geq 65$ years), preoperative KPSS $(</ \geq 80)$, preoperative ACCI, and EOR (complete, incomplete). For survival after the surgery for first recurrence of GB, preoperative KPSS < 80 (HR 2.002 [95\% CI: 1.246-3.216], $P=0.004$ ) and EOR (incomplete resection vs. complete resection: HR 1.611 [95\% CI: 1.036-2.505], $P=0.034)$ were significant prognostic factors. ACCI (HR 0.942 [95\% CI: 0.801-1.104], $P=0.466)$ and age $<65$ years (HR 0.617 [95\% CI 0.339-1.125], $P=0.115$ ) did not show significant results. In a further analysis, preoperative KPSS was removed for multivariate analysis, and only the factors age, EOR, and preoperative ACCI were assessed (Table 2).

\section{Discussion}

ACCI might be an additional prognostic factor for patients with recurrent $\mathrm{GB}$; beneath the well-established KPSS, the ACCI, however, did not show statistical significance. The present study assessed 133 patients with surgery or biopsy for recurrent GB. Although there is a standardized treatment for newly diagnosed GB according to a complete surgical resection if possible, followed by concomitant radiochemotherapy as reported in the

Table 2 Multivariate Cox analysis using ACCl as a categorical variable as well as in dichotomised form

\begin{tabular}{|c|c|c|c|}
\hline & Hazard Ratio & $95 \% \mathrm{Cl}$ & P-Value \\
\hline Age $(>=65$ vs. $<65)$ & 0.62 & $0.34-1.13$ & 0.12 \\
\hline Postoperative KPSS (<80 vs. $>=80)^{*}$ & 2.00 & $1.25-3.22$ & 0.004 \\
\hline Resection (complete/incomplete) & 1.61 & $1.04-2.51$ & 0.034 \\
\hline $\mathrm{ACCl}$ & 0.94 & $0.80-1.11$ & 0.467 \\
\hline \multicolumn{4}{|l|}{$A$} \\
\hline $\operatorname{Age}(>=65$ vs. $<65)$ & 0.74 & $0.41-1.32$ & 0.306 \\
\hline $\mathrm{ACCl}$ & 0.98 & $0.84-1.15$ & 0.84 \\
\hline $\begin{array}{l}\text { Resection (complete/incom- } \\
\text { plete)* }\end{array}$ & 1.74 & $1.12-2.67$ & 0.013 \\
\hline \multicolumn{4}{|l|}{$B$} \\
\hline Age $(>=65$ vs. $<65)$ & 0.80 & $0.50-1.29$ & 0.363 \\
\hline $\begin{array}{l}\text { Resection (complete/incom- } \\
\text { plete)* }\end{array}$ & 1.83 & $1.17-2.85$ & 0.008 \\
\hline ACCI 6.5 & 0.64 & $0.31-1.31$ & 0.219 \\
\hline \multicolumn{4}{|l|}{ C } \\
\hline Age $(>=65$ vs. $<65)$ & 0.75 & $0.46-1.21$ & 0.236 \\
\hline $\begin{array}{l}\text { Resection (complete/incom- } \\
\text { plete)* }\end{array}$ & 1.68 & $1.07-2.64$ & 0.023 \\
\hline ACCI 6.5 & 0.71 & $0.34-1.48$ & 0.359 \\
\hline $\begin{array}{l}\text { Postoperative KPS (<80 vs. } \\
>=80)^{*}\end{array}$ & 1.88 & $1.18-3.01$ & 0.008 \\
\hline
\end{tabular}

Cl Confidence Interval; ${ }^{*} P</=0.05$

A Subanalysis without KPSS; B Subanalysis with the ACCI cut-off of $6.5 ; C$ Subanalysis with the ACCI cut-off of 6.5 and KPSS
EORTC Trial [24], all tumors show recurrence. Important prognostic factors in the case of recurrent GB surgery are age, KPSS, and tumor volume, radiation necrosis at time of re-surgery, and the interval between surgeries $[6,25-32]$. Contrary to these established prognostic factors, in this study only preoperative KPSS and EOR showed an improved OS after first re-resection. Age missed statistical significance. This might be due to the small study cohort and the fact that young patients are offered a re-surgery more easily than older patients. In addition to these prognostic factors, Park et al. developed a preoperative scale for counseling patients considering repeated surgery and their prognosis. This NIH Recurrent GBM Scale comprised the following characteristics: motor/speech/middle cerebral artery score $>2$, KPSS score $\leq 80 \%$, and tumor volume $\geq 50 \mathrm{~cm}^{3}$. Each characteristic was assigned one point. They could show that patients with a score of three points expected a 1-month median survival, those with 1-2 points expected an intermediate survival with 4.5 months, and those with zero points presented the best survival with a median of 10.8 months [29]. The KPSS is used for treatment decisions in patients with recurrent GB in clinical practice. Due to demographic changes and an expanding population of elderly with an increasing incidence rate of $G B$, the patient's age in the case of relapse is also higher. Treatment concepts for elderly patients with recurrent GB in clinical practice may be individualized by taking into account performance status, response to previous regimens, increasing MGMT promoter methylation status, and quality of life with regard to expected toxicities $[33,34]$. Equally, it is apparent that this patient group is usually associated with a higher rate of comorbidities [35]. Therefore, more prognostic factors in addition to the functional status (KPSS) are needed in the preoperative assessment to facilitate decisions in the treatment of these patients. The Charlson Comorbidity Index (CCI) [14] and its further developed age-adapted version (ACCI) [16] are particularly well suited to help classify comorbidities and estimate the risk of death from comorbid disease for use in prognosis. In the present study, the role of ACCI in comparison to KPSS as a prognostic factor in recurrent GB patients was assessed. Several factors, such as surgical resection in relapsing $G B$, the extent of surgical resection (EOR), and the amount of residual tumor volume, influence the outcomes for these patients [36]. The extent of re-resection and preoperative good performance (KPSS) may serve as independent predictors of survival [37-39]. Likewise, evidence from contrast-enhanced residual tumor volume analysis demonstrated significant OS differences between large $(\geq 15 \mathrm{cc})$ and small $(<15 \mathrm{cc})$ tumor sizes in patients in all therapeutic scenarios $[40,41]$. Of the many prognostic 
factors in the case of recurrent GB, in multivariate analysis, preoperative KPSS $(\geq 80 /<80)$ and EOR were the only significant prognostic factors, whereas ACCI missed statistical significance. In recent studies with relapsing head and neck squamous cell carcinoma, which also showed a poor prognosis with a mean survival of 48 months in the case of a high T stage [42], an ACCI of less than 6 was associated with significantly improved survival [43, 44]. As shown in these studies, we also removed the preoperative KPSS for multivariate analysis, and only the factors age, EOR, and preoperative ACCI were assessed. ACCI might be a prognostic factor, but in comparison to the KPSS, it remains weak. An explanation for this may be that the KPSS is more robust and not, or only marginally, influenced by patient age.

\section{Limitations of the study}

The main limitation of this study is the retrospective design that might introduce an unavoidable bias. The validation of prognostic factors for the outcomes and for supporting therapy selection in recurrent GB would ideally have to be randomized and prospective. Therefore, prospective studies should be performed to assess the value of the ACCI in preoperative patient assessment.

\section{Conclusion}

For patients with surgery for recurrent glioblastoma, the ACCI does not add further information about patient's prognosis besides the well-established KPSS and extent of resection.

\section{Acknowledgements}

No acknowledgements required.

\section{Informed consent}

The requirement for study specific written informed consent was waived by the ethics committee (Ethikkommission der Fakultät für Medizin der Technischen Universität München).

\section{Authors' contributions}

Conceptualization: JG, MB. Methodology: MB, SB. Formal analysis and investigation: MB, AKA, SB. Writing- original draft preparation: MB, SB. Writing- review and editing: IJ, YM, SC, JG, BM, BW, TH, FLS. Funding acquisition: no funding. Resources: no other resources. Supervision: BM, JG, SC. All authors read and approved the final manuscript.

\section{Funding}

Open Access funding enabled and organized by Projekt DEAL.

\section{Availability of data and materials}

The datasets used and/or analysed during the current study are available from the corresponding author on reasonable request.

\section{Declarations}

\section{Ethical approval and consent to participate}

This retrospective, non-interventional study was approved by the local medical ethics committee, Technical University Munich, School of Medicine, (No. 5625-12) and is in accordance with the ethical standards of the 1964 Declaration of Helsinki and its later amendments [9].
All patients sign a generally valid declaration of consent for participation in retrospective studies that included consent for the use of their clinical data in any researched completed at our institution upon admission. This consent form was approved by the local medical ethics committee.

\section{Consent for publication}

With the consent for participation, all patients also give their permission for the results obtained to be published.

\section{Competing interests}

JG, BM and SB work as consultants for Brainlab (Brainlab AG, Munich). YMR receives financial research grants from Brain LAB, Carl Zeiss Medical, DepuySynthes, Icotec, Medtronic, Silony, Spineart and Ulrich Medical. Furthermore, YMR works as a consultant for BrainLAB and Icotec.

TH worked as a medical consultant for Brainlab AG (Munich, Germany) until 2016 and is head of scientific collaborations at Smart Reporting GmbH (Munich, Germany)—all unrelated to the present study.

In addition, BM works as a consultant for Medtronic, Spineart, Icotec, Relievant and Depuy/Synthes. In these firms, BM acts as a member of the advisory board. Furthermore, BM reports a financial relationship with Medtronic, Ulrich Medical, Brainlab, Spineart, Icotec, Relievant and Depuy/Synthes. He received personal fees and research grants for clinical studies from Medtronic, Ulrich Medical, Brainlab, Icotec and Relievant. All this occurred independently of the submitted work. BM holds the royalties/patent for Spineart.

All named potential conflicts of interest are unrelated to this study. All other authors declare no conflict of interest.

\section{Author details}

${ }^{1}$ Department of Neurosurgery, Technical University Munich, School of Medicine, Klinikum rechts der Isar, Munich, Germany. ${ }^{2}$ Department of Neuroradiology, Technical University Munich, School of Medicine, Klinikum rechts der Isar, Munich, Germany. ${ }^{3}$ Department of Radiology and Neuroradiology, University of Augsburg, Augsburg, Germany. ${ }^{4}$ Department of Neurosurgery, Hôpitaux Universitaires de Genève, Geneva, Switzerland. ${ }^{5}$ Institute of Clinical Radiology and Nuclear Medicine, University Medical Center Mannheim, Medical Faculty Mannheim, Heidelberg University, Mannheim, Germany. ${ }^{6}$ Department of Neuropathology, Technical University Munich, School of Medicine, Klinikum rechts der Isar, Institute of Pathology, Munich, Germany. ${ }^{7}$ Department of Neurosurgery, Helios Klinikum Berlin Buch, Berlin, Germany. ${ }^{8}$ Department of Radiation Oncology, Technical University Munich, School of Medicine, Klinikum rechts der Isar, Munich, Germany. ${ }^{9}$ Department of Radiation Sciences (DRS) Helmholtz Zentrum Munich, Institute of Innovative Radiotherapy (iRT), Munich, Germany. ${ }^{10}$ German Cancer Consortium (DKTK), Partner Site Munich, Munich, Germany.

Received: 2 November 2020 Accepted: 22 December 2021

Published online: 21 January 2022

\section{References}

1. Barnholtz-Sloan JS, Ostrom QT, Cote D. Epidemiology of brain tumors. Neurol Clin. 2018;36(3):395-419. https://doi.org/10.1016/j.ncl.2018.04.001.

2. Ostrom QT, Cote DJ, Ascha M, Kruchko C, Barnholtz-Sloan JS. Adult Glioma incidence and survival by race or ethnicity in the United States from 2000 to 2014. JAMA Oncol. 2018;4(9):1254-62. https://doi.org/10. 1001/jamaoncol.2018.1789.

3. Minniti G, Amelio D, Amichetti M, Salvati M, Muni R, Bozzao A, et al. Patterns of failure and comparison of different target volume delineations in patients with glioblastoma treated with conformal radiotherapy plus concomitant and adjuvant temozolomide. Radiother Oncol. 2010;97(3):377-81. https://doi.org/10.1016/j.radonc.2010.08.020.

4. Woehrer A, Bauchet L, Barnholtz-Sloan JS. Glioblastoma survival: has it improved? Evidence from population-based studies. Curr Opin Neurol. 2014;27(6):666-74. https://doi.org/10.1097/WCO.0000000000000144.

5. Palmer JD, Bhamidipati D, Shukla G, Sharma D, Glass J, Kim L, et al. Rapid early tumor progression is prognostic in Glioblastoma patients. Am J Clin Oncol. 2019;42(5):481-6. https://doi.org/10.1097/COC.0000000000 000537.

6. Hervey-Jumper SL, Berger MS. Reoperation for recurrent highgrade glioma: a current perspective of the literature. Neurosurgery. 
2014;75(5):491-9; discussion 8-9. https://doi.org/10.1227/NEU.00000 00000000486

7. Ringel F, Pape H, Sabel M, Krex D, Bock HC, Misch M, et al. Clinical benefit from resection of recurrent glioblastomas: results of a multicenter study including 503 patients with recurrent glioblastomas undergoing surgical resection. Neuro-Oncology. 2016;18(1):96-104. https://doi.org/10.1093/ neuonc/nov145.

8. Macedo M, Wenger C, Salvador R, Fernandes SR, Miranda PC. Investigating an alternative ring design of transducer arrays for tumor treating fields (TTFields). Conf Proc IEEE Eng Med Biol Soc. 2016;2016:5168-71. https://doi.org/10.1109/EMBC.2016.7591891.

9. Karnofsky DA, Burchenal JH, et al. Experimental observations on the effects of the nitrogen mustards on neoplastic tissues. Cancer Res. 1947;7(1):50.

10. Sacko A, Hou MM, Temgoua M, Alkhafaji A, Marantidou A, Belin C, et al. Evolution of the Karnosky performance status throughout life in glioblastoma patients. J Neuro-Oncol. 2015;122(3):567-73. https://doi.org/10. 1007/s11060-015-1749-6.

11. Suchorska B, Jansen NL, Linn J, Kretzschmar H, Janssen H, Eigenbrod S, et al. Biological tumor volume in 18FET-PET before radiochemotherapy correlates with survival in GBM. Neurology. 2015;84(7):710-9. https://doi. org/10.1212/WNL.00000000000001262.

12. Yong RL, Wu T, Mihatov N, Shen MJ, Brown MA, Zaghloul KA, et al. Residual tumor volume and patient survival following reoperation for recurrent glioblastoma. J Neurosurg. 2014;121(4):802-9. https://doi.org/ 10.3171/2014.6.JNS132038.

13. Bergqvist J, Iderberg H, Mesterton J, Henriksson R. The effects of clinical and sociodemographic factors on survival, resource use and lead times in patients with high-grade gliomas: a population-based register study. J Neuro-Oncol. 2018;139(3):599-608. https://doi.org/10.1007/ s11060-018-2899-0.

14. Charlson ME, Pompei P, Ales KL, MacKenzie CR. A new method of classifying prognostic comorbidity in longitudinal studies: development and validation. J Chronic Dis. 1987;40(5):373-83. https://doi.org/10.1016/ 0021-9681(87)90171-8.

15. Shuvy M, Zwas DR, Keren A, Gotsman I. Prevalence and impact of concomitant malignancy on outcomes among ambulatory heart failure population. Eur J Clin Investig. 2021;51(2):e13373. https://doi.org/10. 1111/eci.13373.

16. Charlson M, Szatrowski TP, Peterson J, Gold J. Validation of a combined comorbidity index. J Clin Epidemiol. 1994;47(11):1245-51. https://doi.org/ 10.1016/0895-4356(94)90129-5.

17. Martinez C, Jorge AS, Pereira A, Moreno M, Nunez J, Gayoso J, et al. Comorbidities, not age, are predictive of survival after autologous hematopoietic cell transplantation for relapsed/refractory Hodgkin's lymphoma in patients older than 50 years. Ann Hematol. 2017;96(1):9-16. https://doi. org/10.1007/s00277-016-2832-6.

18. Tanvetyanon T, Padhya T, McCaffrey J, Zhu W, Boulware D, Deconti R, et al. Prognostic factors for survival after salvage reirradiation of head and neck cancer. J Clin Oncol. 2009;27(12):1983-91. https://doi.org/10.1200/JCO. 2008.20.0691

19. Mayr R, May M, Burger M, Martini T, Pycha A, Dechet C, et al. The Charlson comorbidity index predicts survival after disease recurrence in patients following radical cystectomy for urothelial carcinoma of the bladder. Urol Int. 2014;93(3):303-10. https://doi.org/10.1159/000362421.

20. General assembly of the world medical a. World medical association declaration of Helsinki: ethical principles for medical research involving human subjects. J Am Coll Dent. 2014;81(3):14-8.

21. Wen PY, Macdonald DR, Reardon DA, Cloughesy TF, Sorensen AG, Galanis E, et al. Updated response assessment criteria for high-grade gliomas: response assessment in neuro-oncology working group. J Clin Oncol. 2010;28(11):1963-72. https://doi.org/10.1200/JCO.2009.26.3541.

22. Louis DN, Perry A, Reifenberger G, von Deimling A, Figarella-Branger D, Cavenee WK, et al. The 2016 World Health Organization classification of tumors of the central nervous system: a summary. Acta Neuropathol. 2016;131(6):803-20. https://doi.org/10.1007/s00401-016-1545-1.

23. von Rosenstiel C, Wiestler B, Haller B, Schmidt-Graf F, Gempt J, Bettstetter $M$, et al. Correlation of the quantitative level of MGMT promoter methylation and overall survival in primary diagnosed glioblastomas using the quantitative MethyQESD method. J Clin Pathol. 2020;73(2):112-5. https:// doi.org/10.1136/jclinpath-2019-206104.
24. Stupp R, Hegi ME, Mason WP, van den Bent MJ, Taphoorn MJ, Janzer RC, et al. Effects of radiotherapy with concomitant and adjuvant temozolomide versus radiotherapy alone on survival in glioblastoma in a randomised phase III study: 5-year analysis of the EORTC-NCIC trial. Lancet Oncol. 2009;10(5):459-66. https://doi.org/10.1016/S1470-2045(09) 70025-7.

25. Bloch O, Han SJ, Cha S, Sun MZ, Aghi MK, McDermott MW, et al. Impact of extent of resection for recurrent glioblastoma on overall survival: clinical article. J Neurosurg. 2012;117(6):1032-8. https://doi.org/10.3171/2012.9. JNS12504.

26. Rusthoven KE, Olsen C, Franklin W, Kleinschmidt-DeMasters BK, Kavanagh $B D$, Gaspar $L E$, et al. Favorable prognosis in patients with high-grade glioma with radiation necrosis: the University of Colorado reoperation series. Int J Radiat Oncol Biol Phys. 2011;81(1):211-7. https://doi.org/10, 1016/j.jijrobp.2010.04.069.

27. Harsh GRt, Levin VA, Gutin PH, Seager M, Silver P, Wilson CB. Reoperation for recurrent glioblastoma and anaplastic astrocytoma. Neurosurgery. 1987;21(5):615-21. https://doi.org/10.1227/00006123-198711000-00002.

28. Barker FG 2nd, Chang SM, Gutin PH, Malec MK, McDermott MW, Prados $M D$, et al. Survival and functional status after resection of recurrent glioblastoma multiforme. Neurosurgery. 1998;42(4):709-20; discussion 20-3. https://doi.org/10.1097/00006123-199804000-00013.

29. Park JK, Hodges T, Arko L, Shen M, Dello lacono D, McNabb A, et al. Scale to predict survival after surgery for recurrent glioblastoma multiforme. J Clin Oncol. 2010;28(24):3838-43. https://doi.org/10.1200/JCO.2010.30. 0582.

30. Woodworth GF, Garzon-Muvdi T, Ye X, Blakeley JO, Weingart JD, Burger PC. Histopathological correlates with survival in reoperated glioblastomas. J Neuro-Oncol. 2013;113(3):485-93. https://doi.org/10.1007/ s1 1060-013-1141-3.

31. Montemurro N, Perrini P, Blanco MO, Vannozzi R. Second surgery for recurrent glioblastoma: a concise overview of the current literature. Clin Neurol Neurosurg. 2016;142:60-4. https://doi.org/10.1016/j.clineuro.2016. 01.010 .

32. Chang SM, Parney IF, McDermott M, Barker FG 2nd, Schmidt MH, Huang W, et al. Perioperative complications and neurological outcomes of first and second craniotomies among patients enrolled in the Glioma outcome project. J Neurosurg. 2003;98(6):1175-81. https://doi.org/10.3171/ jns.2003.98.6.1175.

33. Roth P, Gramatzki D, Weller M. Management of Elderly Patients with Glioblastoma. Curr Neurol Neurosci Rep. 2017;17(4):35. https://doi.org/10. 1007/s11910-017-0740-3.

34. Perry JR, Laperriere N, O'Callaghan CJ, Brandes AA, Menten J, Phillips C, et al. Short-course radiation plus Temozolomide in elderly patients with Glioblastoma. N Engl J Med. 2017;376(11):1027-37. https://doi.org/10. 1056/NEJMoa1611977.

35. Felsberg J, Rapp M, Loeser S, Fimmers R, Stummer W, Goeppert M, et al. Prognostic significance of molecular markers and extent of resection in primary glioblastoma patients. Clin Cancer Res. 2009;15(21):6683-93. https://doi.org/10.1158/1078-0432.CCR-08-2801.

36. Yang CC, Chen PC, Hsu CW, Chang SL, Lee CC. Validity of the age-adjusted charlson comorbidity index on clinical outcomes for patients with nasopharyngeal cancer post radiation treatment: a 5-year nationwide cohort study. PLoS One. 2015;10(1):e0117323. https://doi.org/10.1371/journal. pone. 0117323 .

37. Boje CR, Dalton SO, Primdahl H, Kristensen CA, Andersen E, Johansen J, et al. Evaluation of comorbidity in 9388 head and neck cancer patients: a national cohort study from the DAHANCA database. Radiother Oncol. 2014;110(1):91-7. https://doi.org/10.1016/j.radonc.2013.11.009.

38. Pessina F, Navarria P, Cozzi L, Tomatis S, Riva M, Ascolese AM, et al. Role of surgical resection in recurrent glioblastoma: prognostic factors and outcome evaluation in an observational study. J Neuro-Oncol. 2017;131 (2):377-84. https://doi.org/10.1007/s11060-016-2310-y.

39. Perrini P, Gambacciani C, Weiss A, Pasqualetti F, Delishaj D, Paiar F, et al. Survival outcomes following repeat surgery for recurrent glioblastoma: a single-center retrospective analysis. J Neuro-Oncol. 2017;131(3):585-91. https://doi.org/10.1007/s11060-016-2330-7.

40. Tully PA, Gogos AJ, Love C, Liew D, Drummond KJ, Morokoff AP. Reoperation for recurrent Glioblastoma and its association with survival benefit. Neurosurgery. 2016;79(5):678-89. https://doi.org/10.1227/NEU.00000 00000001338. 
41. Azoulay M, Santos F, Shenouda G, Petrecca K, Oweida A, Guiot MC, et al. Benefit of re-operation and salvage therapies for recurrent glioblastoma multiforme: results from a single institution. J Neuro-Oncol. 2017;132(3):419-26. https://doi.org/10.1007/s1 1060-017-2383-2.

42. Mendenhall WM, Morris CG, Amdur RJ, Hinerman RW, Mancuso AA. Parameters that predict local control after definitive radiotherapy for squamous cell carcinoma of the head and neck. Head Neck. 2003;25(7):535-42. https://doi.org/10.1002/hed.10253.

43. Kim J, Kim S, Albergotti WG, Choi PA, Kaplan DJ, Abberbock S, et al. Selection of ideal candidates for surgical salvage of head and neck squamous cell carcinoma: effect of the Charlson-age comorbidity index and oncologic characteristics on 1-year survival and hospital course. JAMA Otolaryngol Head Neck Surg. 2015;141(12):1059-65. https://doi.org/10. 1001/jamaoto.2015.2158.

44. Chang JH, Wu CC, Yuan KS, Wu ATH, Wu SY. Locoregionally recurrent head and neck squamous cell carcinoma: incidence, survival, prognostic factors, and treatment outcomes. Oncotarget. 2017;8(33):55600-12. https:// doi.org/10.18632/oncotarget.16340.

\section{Publisher's Note}

Springer Nature remains neutral with regard to jurisdictional claims in published maps and institutional affiliations.

- fast, convenient online submission

- thorough peer review by experienced researchers in your field

- rapid publication on acceptance

- support for research data, including large and complex data types

- gold Open Access which fosters wider collaboration and increased citations

- maximum visibility for your research: over $100 \mathrm{M}$ website views per year

At BMC, research is always in progress.

Learn more biomedcentral.com/submissions 